\title{
Mechanism Analysis and Parameter Optimization of Mega-Sub-Isolation System
}

\author{
Xiangxiu Li, ${ }^{1}$ Ping Tan, ${ }^{2}$ Xiaojun Li, ${ }^{1}$ and Aiwen Liu ${ }^{1}$ \\ ${ }^{1}$ Institute of Geophysics, China Earthquake Administration, Beijing 100081, China \\ ${ }^{2}$ Earthquake Engineering Research \& Test Center, Guangzhou University, Guangzhou 510405, China \\ Correspondence should be addressed to Ping Tan; ptan@gzhu.edu.cn
}

Received 8 April 2016; Accepted 24 May 2016

Academic Editor: Nicola Caterino

Copyright (C) 2016 Xiangxiu Li et al. This is an open access article distributed under the Creative Commons Attribution License, which permits unrestricted use, distribution, and reproduction in any medium, provided the original work is properly cited.

\begin{abstract}
The equation of motion of mega-sub-isolation system is established. The working mechanism of the mega-sub-isolation system is obtained by systematically investigating its dynamic characteristics corresponding to various structural parameters. Considering the number and location of the isolated substructures, a procedure to optimally design the isolator parameters of the mega-subisolation system is put forward based on the genetic algorithm with base shear as the optimization objective. The influence of the number and locations of isolated substructures on the control performance of mega-sub-isolation system has also been investigated from the perspective of energy. Results show that, with increase in substructure mass, the working mechanism of the mega-subisolation system is changed from tuned vibration absorber and energy dissipation to seismic isolation. The locations of the isolated substructures have little influence on the optimal frequency ratio but have great influence on the optimal damping ratio, while the number of isolated substructures shows great impact on both the optimal frequency ratio and damping ratio. When the number of the isolated substructures is determined, the higher the isolated substructures, the more the energy that will be consumed by the isolation devices, and with the increase of the number of isolated substructures, the better control performance can be achieved.
\end{abstract}

\section{Introduction}

With the development of economics and the advancement of science and technology, more and more tall buildings and super tall buildings have been built in recent years. The most significant engineering concerns in construction of tall and super tall buildings are the safety of the building structures and the comfort of occupants under external forces such as winds and earthquakes. Isolation technology is known as an effective way to improve the structural seismic response. The objective of seismic isolation is to decouple the structure from the ground motion, preventing the structure from absorbing the earthquake energy. Recently some significant research has been done on the isolation structures. Khoshnoudian and Mehrparvar [1] proposed a new control algorithm to protect nonlinear base-isolated structures against earthquakes. Intensity measures for the seismic response prediction of base-isolated buildings were investigated by Mollaioli et al. [2]. Leopa et al. [3] have done some research studies on damage identification in passive vibroisolation devices, which dealt with the theoretical aspects combined with experimental analysis regarding early damage identification in passive vibroisolation devices. Briman and Ribakov [4] have developed a method for building retrofits, that is, replacing weak conventional columns with low static and dynamic load-carrying capacities by seismic isolation columns. The effectiveness of various control strategies in hybrid base isolation systems including isolators and semiactive variable friction dampers has been investigated by Ribakov [5]. The disorder and damage of base-isolated medical facilities when subjected to near-fault and long-period ground motions have been investigated by Shi et al. [6]. Yan and Chen [7] have studied the seismic performance of midstory isolated structures under near-field pulse-like ground motion, in which a mechanical model has been put forward for this protective system based on the Kelvin pounding model, and a new method has been proposed that synthesizes artificial near-field pulse-like ground motion by combining 
the real near-field nonpulse ground motion with simple equivalent pulses. Ozdemir and Akyuz [8] have analyzed the dynamic responses of isolated structures under bidirectional excitations of near-field ground motions, in which nonlinear response history analyses of a 3-story isolated reinforced concrete building have been carried out under both uni- and bidirectional earthquake excitations of near-field records. A comparative analytical study of several control strategies for semiactive devices installed in base-isolated buildings aiming at reducing earthquake induced vibrations is presented by Oliveira et al. [9]. Castaldo et al. [10] have studied the seismic reliability of a base-isolated structure with friction pendulum isolators considering both isolator properties and earthquake main characteristics as random variables.

For buildings of modest height, implementation of passive control devices offers a potential improvement in structural safety and human comfort. But the structural characteristics common to most tall and super tall buildings, such as high shear rigidity, tend to prevent the application of the traditional control devices. It is still a serious challenge for structural engineers to effectively reduce the structural responses of tall and super tall buildings to further improve the structural safety. A new method for controlling the response of tall and super tall buildings under severe external loads was first introduced by Feng and Mita [11]. Feng and Mita first proposed releasing the connections between the megastructure and the substructures in a megasub-structure, but without installing dampers between the megastructure and the substructures. Chai and Feng [12] subsequently improved this configuration and presented a mega-sub-controlled system based on a conventional megasub-frame and undertook a study of its dynamic response to random wind load excitations. Recently, some studies on the optimal parameters between the substructure and megastructure have been done in order to achieve the best performance by Tian [13]. Lan et al. proposed a multifunction mega-sub-controlled structure; this structure has the function of the mass dampers and base isolation as well as damping energy dissipation. However, there is a lack of theoretical certification [14]. A new connection form between the substructures and megastructure was put forward by Pei and Wang [15], in which the top substructure was connected with the megastructure by dampers. And the studies showed that this new connection form can achieve better damping effect and also can prevent collisions between the top substructures and the megastructure. Qin et al. [16, 17] proposed a new control method, which employs active control and passive dampers together to form a huge control system based on the particular conformation characteristic of mega-sub-controlled system, and also presented a new kind of structural configuration, named mega-sub-controlled structure, which was constructed by applying the structural control principle to structural configuration itself, to form a new structure with obvious response self-control ability, instead of employing the conventional method. Xun'an et al. $[18,19]$ have investigated the control performances of the mega-sub-controlled structure with different control strategies. Lian et al. [20,21] have analyzed the seismic responses of the mega-sub-controlled frame with friction damper, in which friction damped structure is first designed as the substructure in the mega-sub-controlled frame to further reduce structural dynamical responses. A more reasonable and realistic scaled model has been designed to investigate the dynamical characteristics and controlling performances of the mega-sub-controlled system when subjected to strong earthquake motion by Limazie et al. [22], and the control parameters of the structure system, such as the modulated substructures disposition, the damping coefficient ratio, the stiffness ratio, and the mass ratio of the mega-structure and substructure, have been investigated. A parametric study of the relative stiffness ratio and relative mass ratio between the mega-frame and the substructures, as well as the additional column stiffness ratio that influences the response control effectiveness of the mega-sub-controlled structure, was discussed in the literature [23], but the number and locations of the isolated substructures were not considered.

The research of the control mechanism and parameter optimization of the mega-sub-isolation system are insufficient in the past few years. In this paper, the working mechanism of the mega-sub-isolation system is investigated by systematically studying its dynamic characteristics corresponding to various structural parameters. By considering the number and locations of the isolated substructures, the parameter optimization of mega-sub-isolation system has been studied based on the genetic algorithm theory where base shear was used as the optimization objective function. The influence of the number and locations of isolated substructures on the control performance of mega-sub-isolation system has also been investigated from the perspective of energy.

\section{Control Mechanism Study of Mega-Sub-Isolation System}

2.1. Equations of Motion of Mega-Sub-Isolation System. In a mega-sub-isolation system, substructures are connected with the megastructure by isolation devices. For the analysis purposes, the isolation devices are simulated with Kelvin model, and the megastructure is simplified as a series of pointed models, while each substructure is simplified as a lumped mass. Figure 1 shows the simplified analysis model of the mega-sub-isolation system.

According to the D'Alembert principle, motion equation of the analysis model shown in Figure 1 can be established as follows.

For substructure

$$
m_{i} \ddot{x}_{i}+c_{i}\left(\dot{x}_{i}-\dot{y}_{i}\right)+k_{i}\left(x_{i}-y_{i}\right)=-m_{i} \ddot{x}_{g}
$$

where $m_{i}$ is the equivalent mass of each substructure; $c_{i}$ and $k_{i}$ are the equivalent damping and horizontal stiffness of the isolation device, respectively; $\left\{\ddot{x}_{i}\right\},\left\{\dot{x}_{i}\right\}$, and $\left\{x_{i}\right\}$ are the acceleration, velocity, and displacement of the substructure relative to the ground; $\left\{\ddot{y}_{i}\right\},\left\{\dot{y}_{i}\right\}$, and $\left\{y_{i}\right\}$ are the acceleration, 


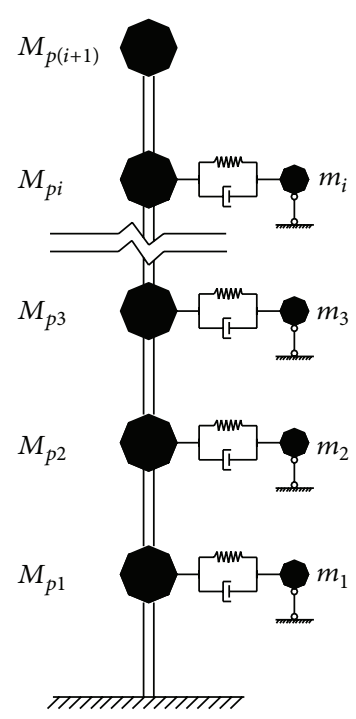

FIgURE 1: Analysis model of mega-sub-isolation system.

velocity, and displacement of the megastructure relative to the ground; $\ddot{x}_{g}$ is the ground motion acceleration.

For megastructure

$$
\begin{gathered}
{\left[M_{p}\right]\{\ddot{y}\}+\left[C_{p}\right]\{\dot{y}\}+\left[K_{p}\right]\{y\}} \\
=-\left[M_{p}\right]\{I\} \ddot{x}_{g}+\left\{f_{s}\right\}
\end{gathered}
$$

in which $\{I\}$ represents the unit vector; $\left\{f_{s}\right\}$ is the force vector (substructures apply to the megastructures); $\left[M_{p}\right]$, $\left[C_{p}\right]$, and $\left[K_{p}\right]$ are the equivalent mass, equivalent damping, and equivalent stiffness of each megastructure, respectively. There is no substructure installed at the first floor of the megastructure because the bottom story of substructure is supported on the ground, and its movement will not directly influence the structural responses. So the number of the substructures is fewer than that of the megastructures by one. The mass matrix, stiffness matrix of the megastructure, and the force vector can be expressed as follows, and the damping matrix of the megastructure is determined by the Rayleigh damping:

$$
\begin{aligned}
{\left[M_{p}\right] } & =\operatorname{diag}\left[M_{p 1}, M_{p 2}, \ldots, M_{p i+1}\right], \\
{\left[K_{p}\right] } & =\operatorname{diag}\left[K_{p 1}, K_{p 2}, \ldots, K_{p i+1}\right], \\
\left\{f_{s}\right\} & =\left[f_{1}, f_{2}, \ldots, f_{i}\right]^{T}, \\
f_{i} & =c_{i}\left(\dot{x}_{i}-\dot{y}_{i}\right)+k_{i}\left(x_{i}-y_{i}\right) .
\end{aligned}
$$

According to (1) and (2), the motion equation of the analysis model shown in Figure 1 is given as

$$
[M]\{\ddot{z}\}+[C]\{\dot{z}\}+[K]\{z\}=-[M]\{I\} \ddot{x}_{g},
$$

where $\{z\}=\left[\{x\}^{T}\{y\}^{T}\right]^{T}$, and the mass matrix, stiffness matrix, and damping matrix of the mega-sub-isolation system can be obtained as follows:

$$
\begin{aligned}
& {[M]=\operatorname{diag}\left(\left[m_{i}\right],\left[M_{p(i+1)}\right]\right) \text {, }} \\
& {[K]=\left[\begin{array}{ccc}
{\left[k_{i}\right]} & -\left[k_{i}\right] & \\
-\left[k_{i}\right] & {\left[K_{p i}\right]+\left[k_{i}\right]} & -K_{p i} \\
& -K_{p i} & K_{p(i+1)}
\end{array}\right],} \\
& {[C]=\left[\begin{array}{ccc}
{\left[c_{i}\right]} & -\left[c_{i}\right] & \\
-\left[c_{i}\right] & {\left[C_{p i}\right]+\left[c_{i}\right]} & -C_{p i} \\
& -C_{p i} & C_{p(i+1)}
\end{array}\right] .}
\end{aligned}
$$

2.2. Control Mechanism Analysis of Mega-Sub-Isolation System. A typical project is selected as an example [14], which is composed of five mega-stories and the substructures are attached to megastructure from the second floor to the fifth floor. The mass and shear stiffness of each megastructure are $9 \times 10^{5} \mathrm{~kg}$ and $9 \times 10^{7} \mathrm{~N} / \mathrm{m}$, respectively, and the mass of top megastructure is $4.5 \times 10^{5} \mathrm{~kg}$. The mass of each substructure is determined by the mass ratio $u$, the frequency ratio $f$ is defined as the ratio of the substructure's frequency to the firstorder frequency of the megastructure, and each substructure has the same parameter values. When the megastructure is simplified as a series of particle-based models, its first period is $2 \mathrm{~s}$, and the fundamental period of the structure is $2.8 \mathrm{~s}$ when the substructures are rigidly connected with the megastructures.

The modal analysis results of the structure when the mass ratio $u=1$ and frequency ratio $f=0.8$ are shown in Table 1 and Figure 2. It can be observed from Table 1 that the first mode and the fifth mode are the main vibration modes of the structure, and these two vibration modes are the global motion of the structure, while the others are local modes of the substructure or megastructure, which can also be seen from Figure 2. Therefore we believe that the control mechanism of the mega-sub-isolation system is related to these two vibration modes.

Figure 3 shows the relationship between the modal mass participation factors and mass ratio and the relationship between the modal mass participation factors and frequency ratio. From Figure 3, it can be confirmed that the first vibration mode and the fifth vibration mode are the main modes of the structure and it is found that when the frequency ratio increases, the modal mass participation factor of the first vibration mode will increase, while that of the fifth vibration mode will decrease.

In order to study the control mechanism of the megasub-isolation system, a 2-DOF equivalent model is adopted based on the modal analysis results. The mass of the bottomstructure in the equivalent model is the total mass of the megastructures, the first-order equivalent stiffness of the megastructure is adopted as the stiffness of the bottomstructure, and the mass of the superstructure is determined by the mass ratio $u$. The connection between the superstructure and bottom-structure is simulated by a Kelvin model. 
TABLE 1: Modal analysis results of mega-sub-isolation system.

\begin{tabular}{lccc}
\hline Modes & Period (s) & Modal mass participation factors & Cumulative mass participation factors \\
\hline 1 & 4.7173 & 0.7828 & 0.7828 \\
2 & 2.8245 & 0.0450 & 0.8278 \\
3 & 2.6443 & 0.0098 & 0.8376 \\
4 & 2.5993 & 0.0018 & 0.8394 \\
5 & 1.0868 & 0.1067 & 0.9461 \\
6 & 0.6168 & 0.0395 & 0.9856 \\
7 & 0.4230 & 0.0112 & 0.9968 \\
8 & 0.3417 & 0.003 & 0.9998 \\
9 & 0.3099 & 0.0003 & 1.0000 \\
\hline
\end{tabular}
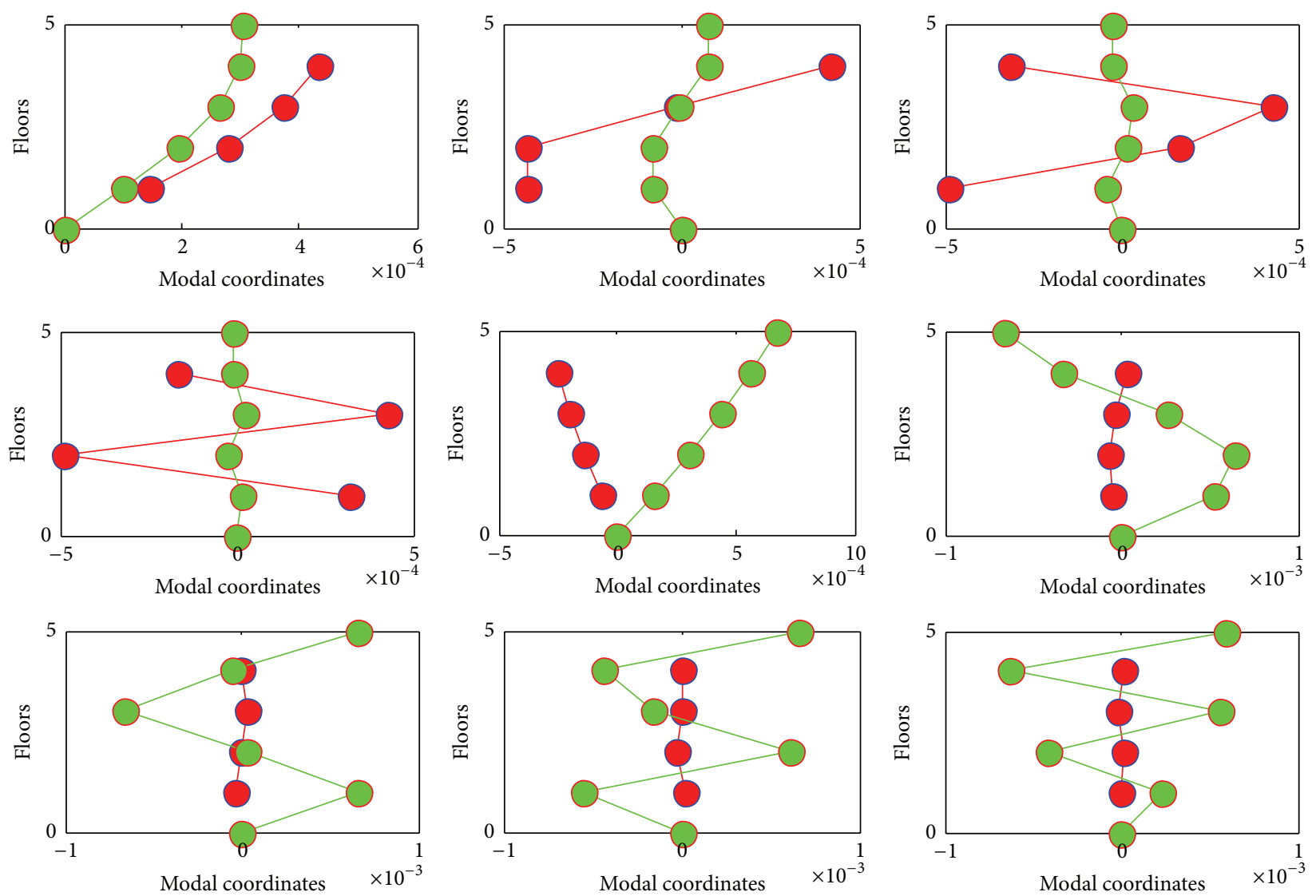

Figure 2: Mode shapes of mega-sub-isolation system.

From Figure 4, it can be seen that the relationship between the modal mass participation factors and frequency ratio of the mega-sub-isolation system is consistent with that of the 2 -DOF equivalent model when the mass ratio is taken as $u=0.5, u=2$, and $u=4$. Then, the 2 -DOF equivalent model can be used to explain the control mechanism of the megasub-isolation system; that is, the working mechanism of the mega-sub-isolation system is changed from tuned vibration absorber and energy dissipation to seismic isolation with increase in substructure mass, according to the literature [24], in which the working mechanism of the 2-DOF equivalent model has been systematically investigated.

\section{Parameters Optimization}

Base shear is very important in earthquake resistant design of building structures. As for isolation system, changing the stiffness and damping of isolators will shift the dynamic characteristic of the system and the distribution of the story shear in the system. In this paper, a procedure to optimally 

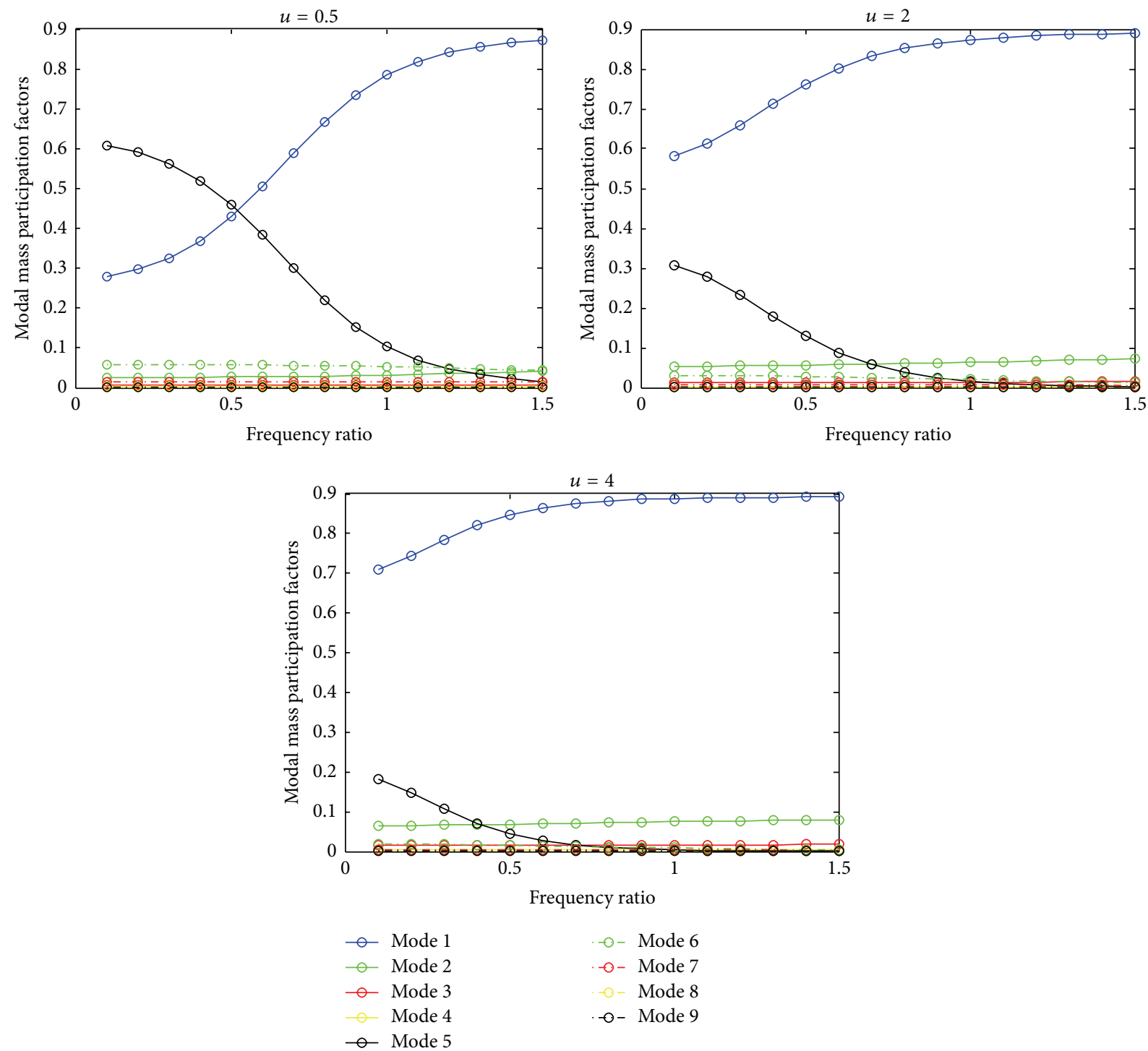

FIGURE 3: Mass participation factors of mega-sub-isolation system.

design the isolator parameters of the mega-sub-isolation system is put forward using the genetic algorithm based on the minimum base shear variance criterion. by

The base shear of the mega-sub-isolation system is given

$$
F_{v}=C_{1} \dot{x}_{1}+K_{1} x_{1},
$$

where $C_{1}$ and $K_{1}$ are the damping and stiffness of the bottom megastructure, respectively. Assuming earthquake excitation to be a stationary stochastic process with zero mean, the responses $\dot{x}_{1}, x_{1}$ can also be considered as two statistically stationary processes with zero mean. According to superposition principle of a stationary stochastic process, the following formulas can be achieved:

$$
\begin{aligned}
& \bar{F}_{v}=C_{1} \overline{\dot{x}}_{1}+K_{1} \bar{x}_{1}, \\
& \bar{F}_{v}^{2}=C_{1}^{2} \overline{\dot{x}}_{1}^{2}+K_{1}^{2} \bar{x}_{1}^{2}+\operatorname{Re}\left(2 K_{1} C_{1} \overline{\dot{x}}_{1} \bar{x}_{1}\right),
\end{aligned}
$$

where "-" represents a mean value of a variable and $\operatorname{Re}(*)$ means taking the real part of complex number. Let $S_{\ddot{x}_{g}}(\omega)$ represent the power spectral density function of seismic excitation and let $H_{\bar{x}_{1}}(\omega), H_{\bar{x}_{1}}(\omega)$ represent the transfer functions of the displacement response and velocity response of the bottom megastructure, respectively, which can be obtained by complex modal analysis methods [25]. The mean square value of the velocity response, the displacement response and the mean value of product $\overline{\dot{x}}_{1} \bar{x}_{1}$ can be evaluated as follows by stochastic vibration method:

$$
\begin{aligned}
& \overline{\dot{x}}_{1}^{2}=\int_{-\infty}^{+\infty} S_{\bar{x}_{1}}(\omega) d \omega=\int_{-\infty}^{+\infty} S_{\ddot{x}_{g}}(\omega)\left|H_{\bar{x}_{1}}(\omega)\right|^{2} d \omega, \\
& \bar{x}_{1}^{2}=\int_{-\infty}^{+\infty} S_{\bar{x}_{1}}(\omega) d \omega=\int_{-\infty}^{+\infty} S_{\ddot{x}_{g}}(\omega)\left|H_{\bar{x}_{1}}(\omega)\right|^{2} d \omega,
\end{aligned}
$$



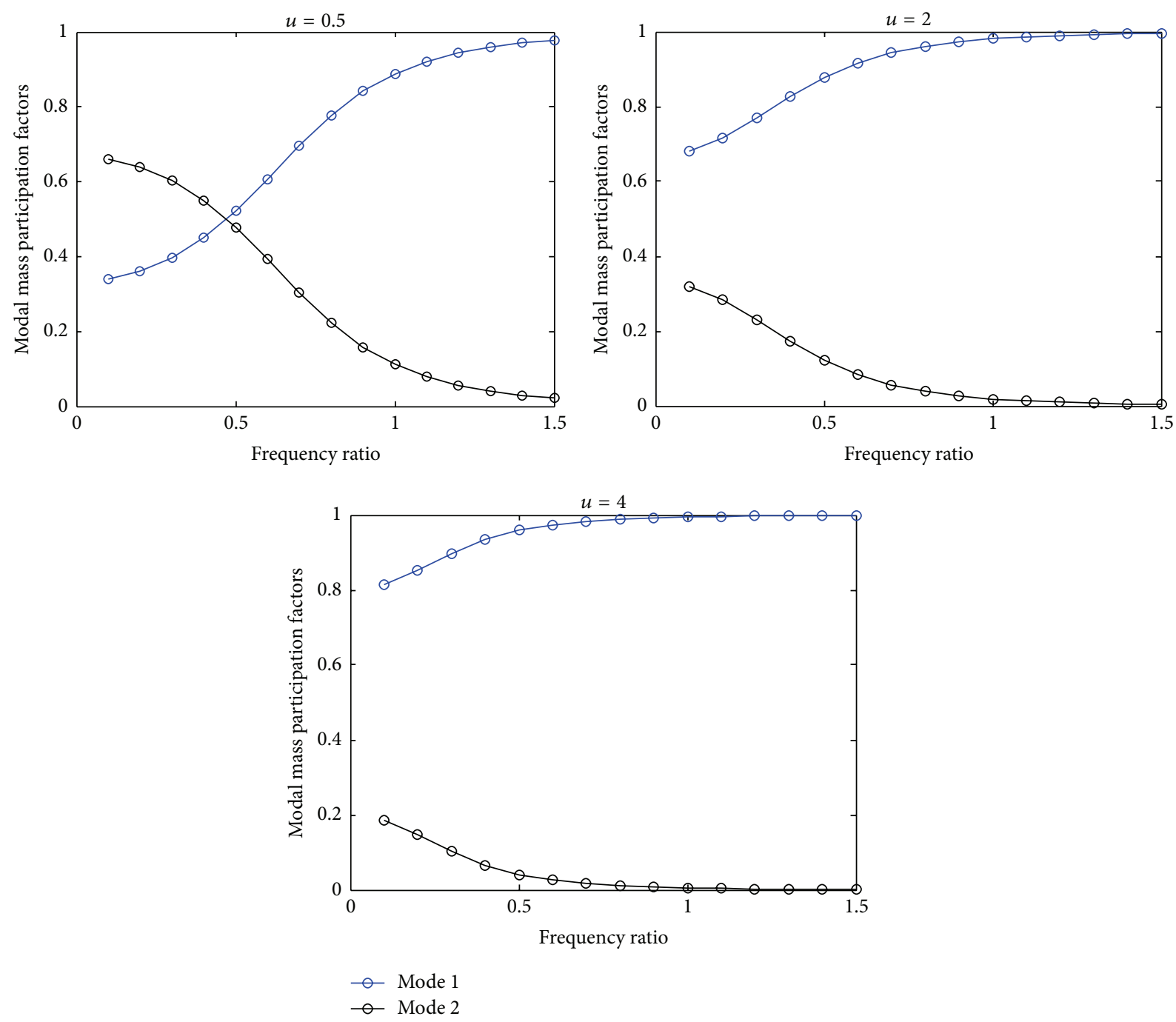

FIGURE 4: Mass participation factors of 2-DOF equivalent model.

$$
\begin{aligned}
\overline{\dot{x}}_{1} \bar{x}_{1} & =\int_{-\infty}^{+\infty} S_{\overline{\dot{x}}_{1} \bar{x}_{1}}(\omega) d \omega \\
& =\int_{-\infty}^{+\infty}\left|H_{\bar{x}_{1}}(\omega)\right| S_{\ddot{x}_{g}}(\omega)\left|H_{\bar{x}_{1}}(\omega)\right|^{*} d \omega .
\end{aligned}
$$

Noting that $S_{\overline{\dot{x}}_{1} \bar{x}_{1}}(\omega)$ is the complex conjugate function, then only the real part of $S_{\bar{x}_{1} \bar{x}_{1}}(\omega)$ contributes to the integration in (10). The power spectral function of the base shear of the mega-sub-isolation system can be obtained by the formula $S_{F_{v}}(\omega)=\bar{F}_{v}^{2}$. The base shear variance is given by

$$
\sigma_{F_{v}}^{2}=\int_{-\infty}^{\infty} S_{F_{v}}(\omega) d \omega
$$

In order to minimize the base shear of the mega-sub-isolation system, the optimal isolator parameters such as frequency ratio $f$ and isolator damping ratio $\xi$ can be solved by a nonlinear mathematical programming method:

$$
\begin{array}{ll}
\min _{f, \xi} & \sigma_{F_{v}}^{2}(f, \xi) \\
\text { s.t. } & \xi_{\min } \leq \xi \leq \xi_{\max } \\
& f_{\min } \leq f \leq f_{\max },
\end{array}
$$

where $f_{\min }$ and $f_{\max }$ represent the lower and upper limit of the frequency ratio which are taken as 0.01 and 1.2, respectively, and $\xi_{\min }, \xi_{\max }$ represent the lower and upper limit of the damping ratio which are taken as 0.01 and 0.3 , respectively. The damping ratio of the megastructure is supposed as 0.05. A modified Kanai-Tajimi model suggested by $\mathrm{Hu}$ Yuxian is employed as the stochastic ground motion model, and the parameters of $S_{0}, w_{g}, \xi_{g}$, and $w_{c}$ are taken as $15.74 \mathrm{~cm}^{2} /\left(\mathrm{rad} \cdot \mathrm{s}^{3}\right), 19.07 \mathrm{rad} / \mathrm{s}, 0.784$, and $2.015 \mathrm{rad} / \mathrm{s}$, respectively. Figure 5 shows the optimization process by genetic 


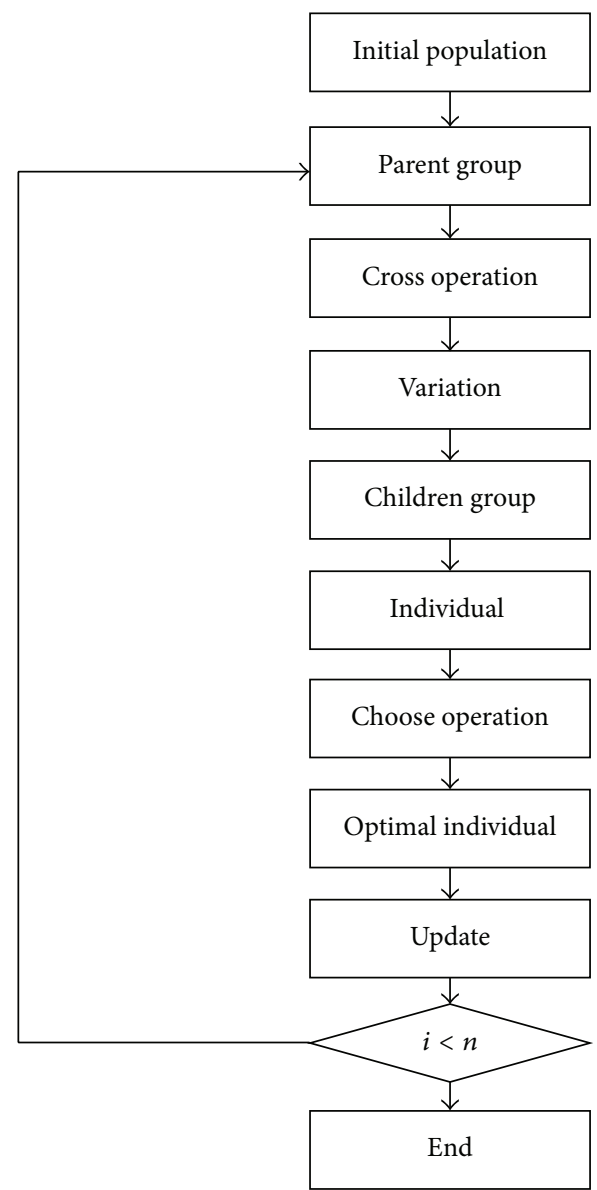

FIGURE 5: Optimization process by genetic algorithm method.

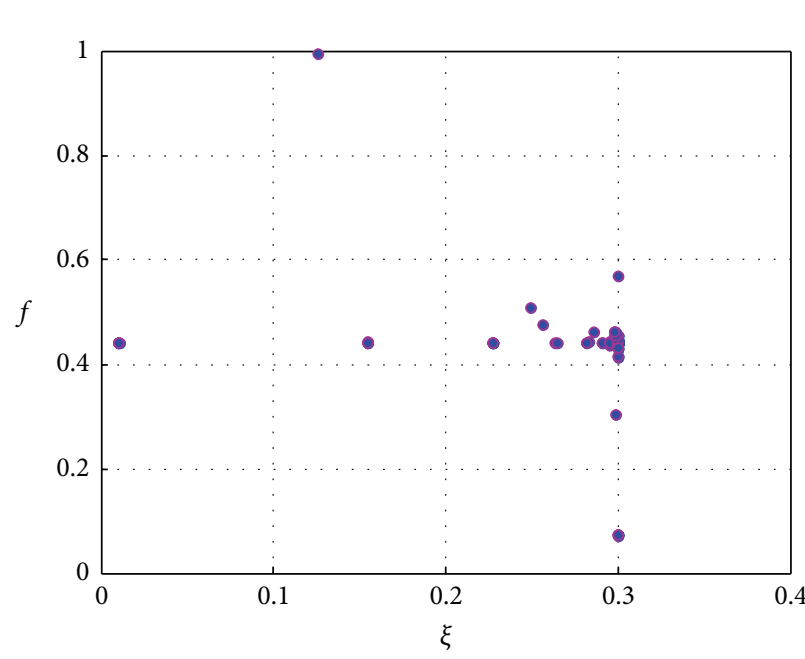

(a) Case of parameter aggregation

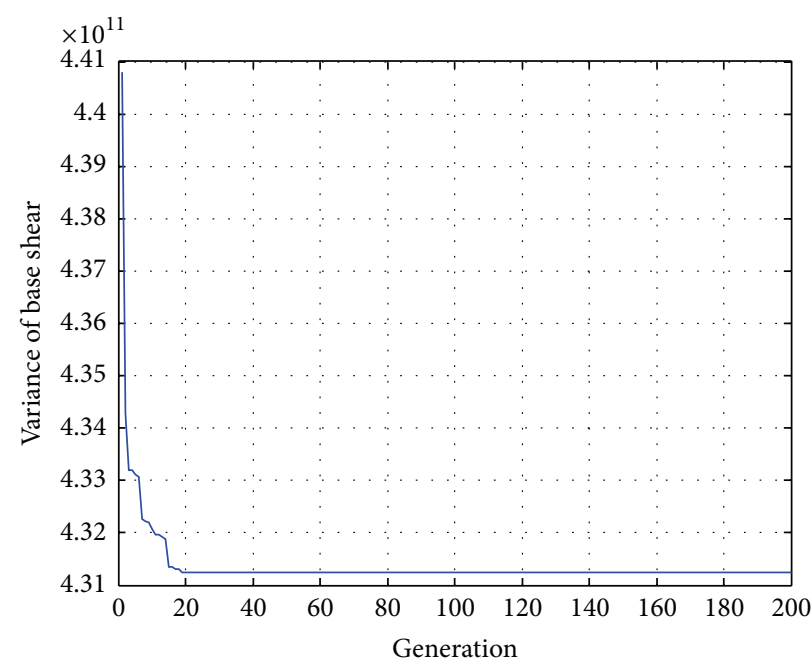

(b) Target value evolution

FIGURE 6: Optimization results of $u=1$.

algorithm method and Figure 6 shows the optimization results when the mass ratio $u$ is taken as 1 .

As can be seen from Figure 6(b), the convergence rate of the genetic algorithm is fast, and an optimal design can be obtained in less than 50 generations. From Figure 6(a), it can be seen that the optimal values of the frequency ratio and damping ratio are 0.44 and 0.3 , respectively, when the mass ratio $u$ is taken as 1 . 
TABLE 2: Optimal damping ratio and optimal frequency ratio of substructures.

\begin{tabular}{cccccccccccccc}
\hline \multicolumn{2}{c}{ Programs } & 5 & 4 & 3 & 2 & 4,5 & 3,5 & 2,5 & $3,4,5$ & $2,4,5$ & $2,3,4,5$ \\
\hline \multirow{2}{*}{$\mu=0.5$} & $f_{\text {opt }}$ & 0.8037 & 0.8143 & 0.8216 & 0.8409 & 0.7121 & 0.7236 & 0.7564 & 0.6451 & 0.6644 & 0.61 \\
& $\xi_{\text {opt }}$ & 0.1490 & 0.1438 & 0.1111 & 0.0778 & 0.1881 & 0.1747 & 0.1623 & 0.2040 & 0.1933 & 0.2700 \\
\hline \multirow{2}{*}{$\mu=1$} & $f_{\text {opt }}$ & 0.7617 & 0.7750 & 0.7890 & 0.8215 & 0.6344 & 0.6505 & 0.6986 & 0.5417 & 0.5687 & 0.4400 \\
& $\xi_{\text {opt }}$ & 0.1792 & 0.1443 & 0.1293 & 0.0900 & 0.2181 & 0.2013 & 0.1879 & 0.2313 & 0.2183 & 0.300 \\
\hline \multirow{2}{*}{$\mu=2$} & $f_{\text {opt }}$ & 0.7239 & 0.7430 & 0.7620 & 0.7955 & 0.5608 & 0.5832 & 0.6456 & 0.4410 & 0.4792 & 0.2900 \\
& $\xi_{\text {opt }}$ & 0.1959 & 0.1472 & 0.1423 & 0.1009 & 0.2387 & 0.2191 & 0.2056 & 0.2460 & 0.2308 & 0.300 \\
\hline
\end{tabular}
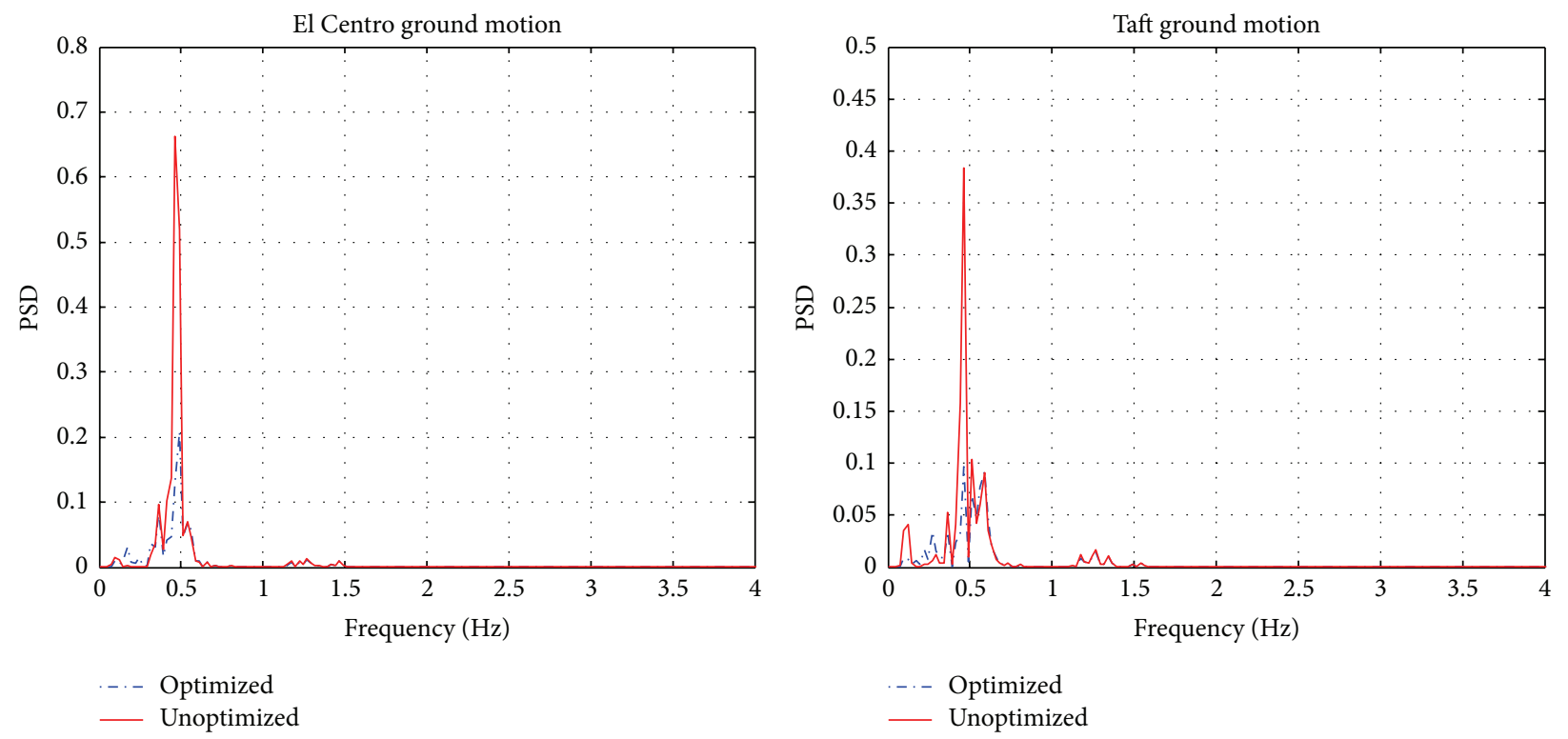

Figure 7: Power spectral density for displacement of top megastructure.

The optimal results with the changes of the number and location of the isolated substructures can also be obtained by this method, which are shown in Table 2.

The numbers shown in Table 2 represent the isolated floors of the substructures; for example, number 2 indicates that the second floor of the substructure is connected with the megastructure by isolation device, and the other substructures are rigidly connected with the megastructures; numbers 4 and 5 indicate that the fourth and the fifth floors of the substructures are connected with the megastructure by isolation device, while the other substructures are rigidly connected with the megastructures. From Table 2, it can be seen that the locations of isolated substructures have little influence on the optimal frequency ratio but have great influence on the optimal damping ratio; when the location of the isolated substructures is lower, the optimal damping ratio shows a trend of decreasing, while the number of isolated substructures shows great impact on both the optimal frequency ratio and damping ratio. With the increasing number of the isolated substructures, the optimal frequency ratio decreases, and the optimal damping ratio increases.

Meanwhile, the mass ratio shows great impact on both the optimal frequency ratio and optimal damping ratio; for the same arrangement scheme of the isolated substructures, the optimal frequency ratio decreases, and the optimal damping ratio increases with the increase of mass ratio.

After the parameters optimization, the power spectral density for displacement of top megastructure and the power spectral density for acceleration of top substructure are compared to those before optimization, as shown in Figures 7 and 8. From Figures 7 and 8, it can be seen that the structural responses after parameter optimization can be reduced obviously compared with that before parameter optimization, so these optimization results can give useful information to designers.

\section{Energy Equation}

In accordance with the energy balance principle, the energy of each part of structure can be obtained by taking integration for the relative displacement $z$ of (4) on both sides at the same time as follows:

$$
E_{K}+E_{D}+E_{P}+E_{T}=E_{I}
$$

in which the total kinetic energy of the structure is defined by $E_{K}=(1 / 2) \dot{z}^{T} M \dot{z}$, the damping energy is $E_{D}=\int \dot{z}^{T} C \dot{z} d t$, and the elastic strain energy of the structure is defined by 

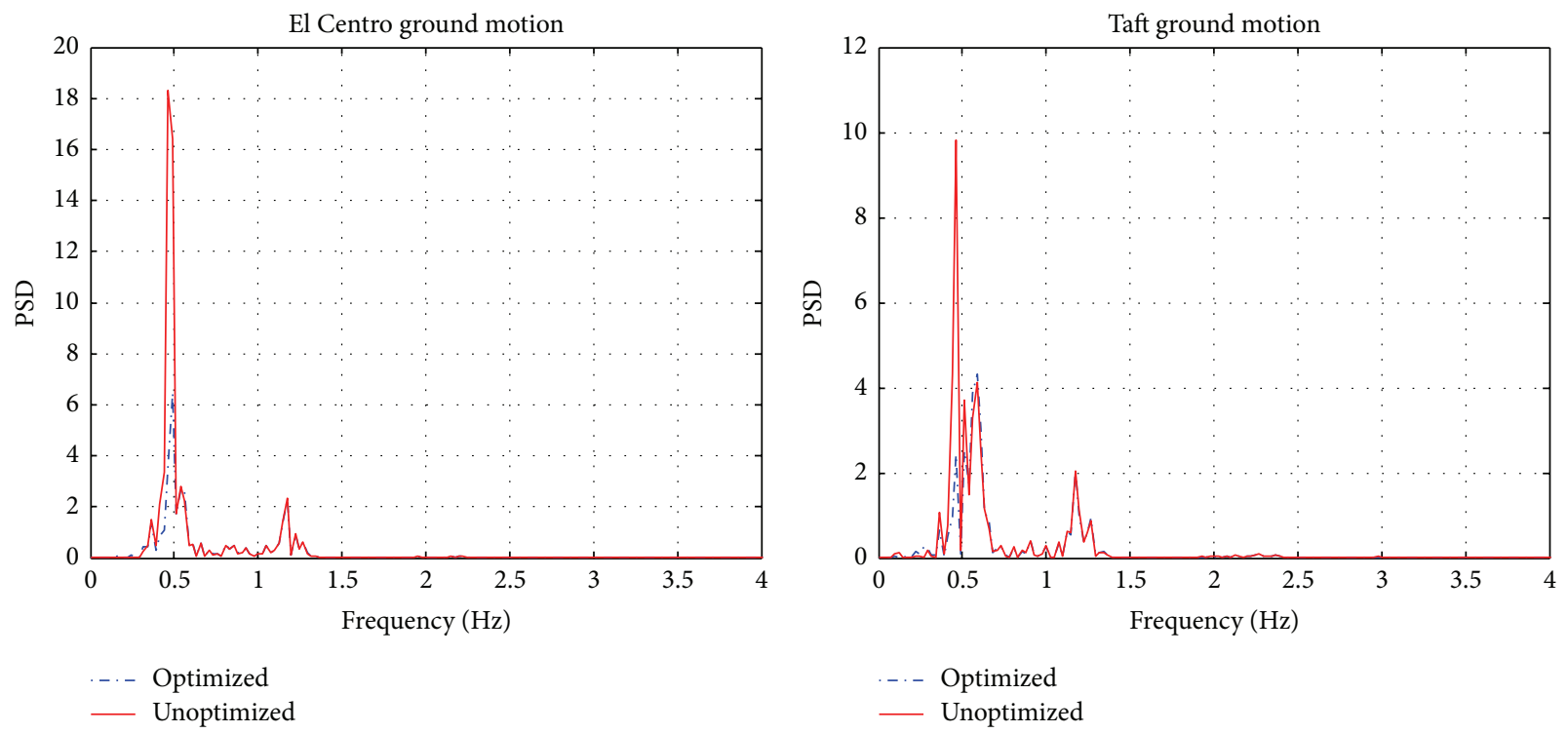

FIGURE 8: Power spectral density for acceleration of top substructure.

TABLE 3: Influence of the number and locations of isolated substructures on control performance under El Centro ground motion.

\begin{tabular}{|c|c|c|c|c|c|}
\hline Programs & $\begin{array}{l}\text { Maximum displacement of } \\
\text { top main structure }(\mathrm{m})\end{array}$ & $\begin{array}{l}\text { Maximum acceleration of } \\
\text { top substructure }\left(\mathrm{m} / \mathrm{s}^{2}\right)\end{array}$ & $\begin{array}{l}\text { Total input energy } \\
\times 10^{6}(\mathrm{~J})\end{array}$ & $\begin{array}{l}\text { Transfer energy } \\
\times 10^{6}(\mathrm{~J})\end{array}$ & Ratio (\%) \\
\hline 5 & 0.2485 & 4.6909 & 4.0509 & 2.6134 & 64.51 \\
\hline 4 & 0.2583 & - & 4.6270 & 2.6066 & 56.33 \\
\hline 3 & 0.2683 & - & 4.0293 & 1.7367 & 43.10 \\
\hline 2 & 0.2792 & - & 4.0063 & 1.4347 & 35.81 \\
\hline 4,5 & 0.1905 & 4.7294 & 3.0926 & 2.4105 & 77.94 \\
\hline 3,5 & 0.1938 & 4.8097 & 3.1616 & 2.3381 & 73.95 \\
\hline 2,5 & 0.2299 & 5.3732 & 3.2344 & 2.0418 & 63.13 \\
\hline $3,4,5$ & 0.1565 & 3.4037 & 3.0567 & 2.7649 & 90.45 \\
\hline $2,4,5$ & 0.1812 & 3.3913 & 2.8621 & 2.2933 & 80.13 \\
\hline $2,3,4,5$ & 0.1207 & 0.7740 & 2.3153 & 2.2736 & 98.20 \\
\hline
\end{tabular}

$E_{P}=\int z^{T} K d z$; at the same time, $E_{I}=-\int \ddot{x}_{g}^{T} M d z$ is defined as the total input energy, and $E_{T}=\int\left[c_{1}\left(\dot{x}_{1}-\dot{y}_{1}\right)+k_{1}\left(x_{1}-\right.\right.$ $\left.\left.y_{1}\right)\right] d y_{1}+\cdots+\int\left[c_{i}\left(\dot{x}_{i}-\dot{y}_{i}\right)+k_{i}\left(x_{i}-y_{i}\right)\right] d y_{i}$ is defined as the transfer energy.

\section{Influence of the Number and Locations of Isolated Substructures on Control Performance}

The number and locations of isolated substructures are important factors influencing the damping effect of the megasub-isolation system. Ten layout programs of the isolated substructures are adopted in this paper and, based on the optimization results obtained from Section 2, the maximum displacement of top megastructure, the maximum acceleration of top substructure, the total input energy of the system, and the transfer energy of the substructure have been calculated when the mass ratio $u$ is taken as 1 , which are shown in Tables 3 and 4. Both the El Centro ground motion and Taft ground motion are employed for the seismic excitation and the PGA of them are taken as $0.4 \mathrm{~g}$.
It can be seen from Tables 3 and 4 that when the number of the isolated substructures is given, locations of isolated substructures have little effect on the maximum displacement of the top megastructure, the maximum acceleration of the top substructure, and the total input energy, but they do have great impact on the transfer energy of substructure, and the transfer energy of substructure is larger when the substructures are located in the upper part of the system. The larger transfer energy of substructure indicates that the more energy consumed by the isolators, the less energy consumed by the megastructure itself when the amount of the total input energy is determined, and thus the safety of the megastructure can be enhanced.

The number of the isolated substructures shows great impact on the control performance of the mega-sub-isolation system. With the increase of the number of isolated substructures, the maximum displacement of the top megastructure, the maximum acceleration of the top substructure, and the total input energy decrease, while the transfer energy increases. Figure 9 shows the average values of maximum displacement of top megastructure, maximum acceleration of top substructure, the total input energy of the system, and 
TABLE 4: Influence of the number and locations of isolated substructures on control performance under Taft ground motion.

\begin{tabular}{|c|c|c|c|c|c|}
\hline Programs & $\begin{array}{l}\text { Maximum displacement of } \\
\text { top main structure }(\mathrm{m})\end{array}$ & $\begin{array}{l}\text { Maximum acceleration of } \\
\text { top substructure }\left(\mathrm{m} / \mathrm{s}^{2}\right)\end{array}$ & $\begin{array}{c}\text { Total input energy } \\
\times 10^{6}(\mathrm{~J}) \\
\end{array}$ & $\begin{array}{c}\text { Transfer energy } \\
\times 10^{6}(\mathrm{~J}) \\
\end{array}$ & Ratio (\%) \\
\hline 5 & 0.2145 & 3.4452 & 2.6300 & 1.8100 & 68.65 \\
\hline 4 & 0.2150 & - & 2.6512 & 1.6200 & 61.13 \\
\hline 3 & 0.2230 & - & 2.7239 & 1.5271 & 56.10 \\
\hline 2 & 0.2310 & - & 2.9320 & 1.3658 & 46.58 \\
\hline 4,5 & 0.2073 & 4.5531 & 2.2600 & 1.4202 & 62.76 \\
\hline 3,5 & 0.2152 & 4.7848 & 2.4763 & 1.3413 & 54.16 \\
\hline 2,5 & 0.2214 & 4.8455 & 2.5872 & 1.4460 & 55.80 \\
\hline $3,4,5$ & 0.1742 & 3.0521 & 2.3292 & 1.9363 & 83.13 \\
\hline $2,4,5$ & 0.1816 & 3.0168 & 2.2393 & 1.6692 & 74.53 \\
\hline $2,3,4,5$ & 0.1200 & 0.73 & 2.1208 & 1.8520 & 86.12 \\
\hline
\end{tabular}

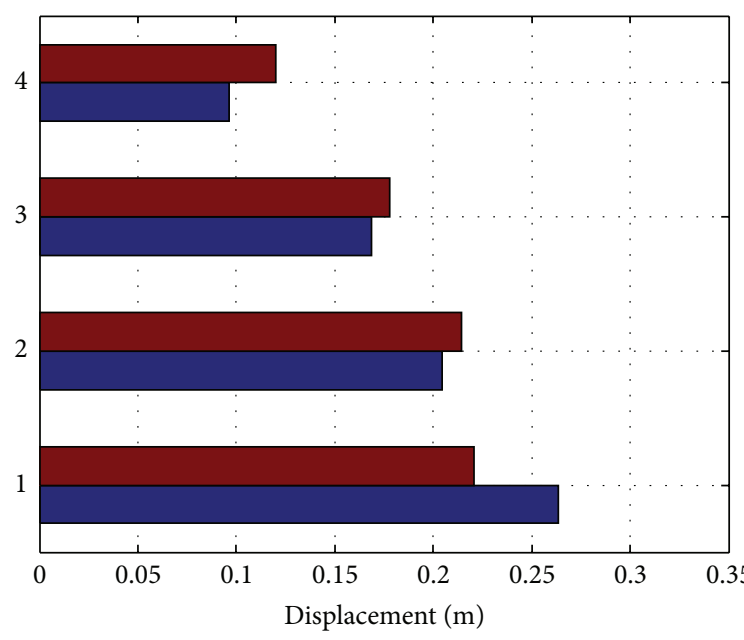

El Centro

$\square$ Taft

(a) Comparison of the average displacement

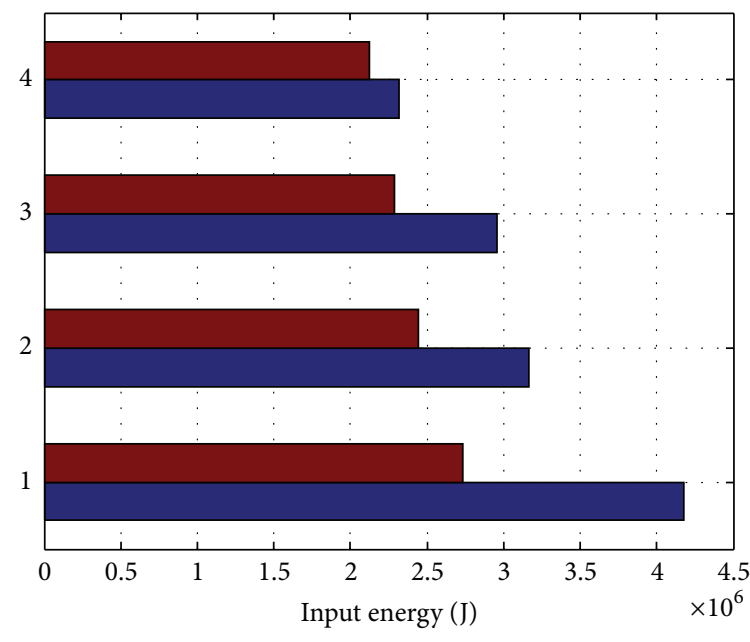

El Centro

$\square$ Taft

(c) Comparison of the average input energy

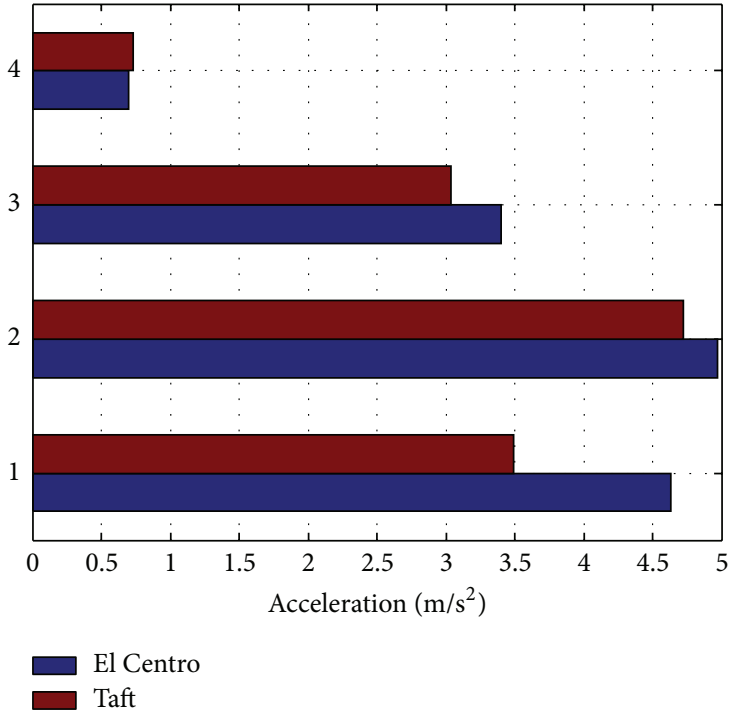

(b) Comparison of the average acceleration

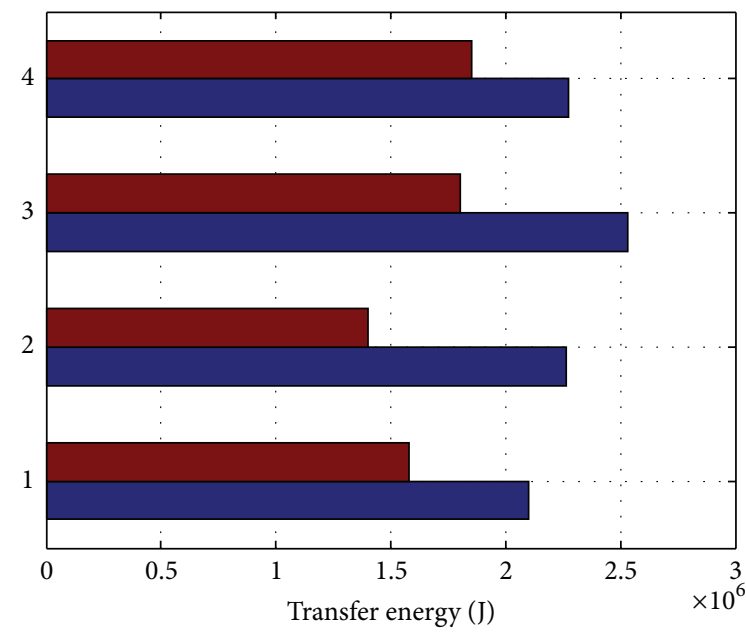

El Centro

Taft

(d) Comparison of the average transfer energy

FIGURE 9: Comparison of average values. 
the transfer energy of the substructure with the changes of the number of isolated substructures. The number in $y$-axis represents the number of the isolated substructures. From Figure 9, it can be confirmed that the number of isolated substructures can influence the control performance of the mega-sub-isolation system greatly and, with the increasing number of isolated substructures, the average values of maximum displacement of top megastructure and the total input energy show a decreasing trend, while the average value of the transfer energy presents the opposite trend. That is, when the number of isolated substructures increases, the total input energy can be reduced and larger energy can be transferred to the substructure which is consumed by the isolation devices, and then the energy consumed by the megastructure itself becomes less. Therefore, in practical engineering applications, all the substructures should be connected with the megastructures by isolation devices in order to achieve the best control performance.

\section{Conclusions}

The control mechanism of the mega-sub-isolation system has been studied from its dynamic characteristics in this paper, and the parameters optimization and the control performance of a mega-sub-isolation system have also been studied when the number and locations of the isolated substructures are different. The following conclusions can be made.

With increasing substructure mass, the working mechanism of the mega-sub-isolation system changes from tuned vibration absorber and energy dissipation to seismic isolation, which is confirmed by theoretical analysis.

Locations of isolated substructures have little influence on the optimal frequency ratio and have great influence on the optimal damping ratio, while the number of isolated substructures and the mass ratio show great impact on both the optimal frequency ratio and damping ratio. The results of parameter optimization can give some useful design suggestions to this novel system.

When the number of isolated substructures is given, locations of the isolated substructures have little effect on the maximum displacement of the top megastructure, the maximum acceleration of the top substructure, and the total input energy, but they have great impact on the transfer energy of substructure, and the transfer energy of substructure is larger when the isolated substructures are located in the upper part of the system. That is, when the isolated substructures are located in the upper part of the structure, more energy will be consumed by the isolation devices. With the increase of the number of isolated substructures, the maximum displacement of top main structure and the total input energy show a decreasing trend, but the transfer energy presents the opposite trend. That is, the more the isolated substructures are, the better the control performance can be achieved. Hence, in practical engineering applications, when the number of isolated substructures is determined, the isolation devices should be installed in the upper substructures and, in order to achieve the best control performance, all the substructures should be connected to the megastructures with isolation devices.

\section{Competing Interests}

The authors declare that there are no competing interests regarding the publication of this paper.

\section{Acknowledgments}

The work was primarily supported by the National Basic Research Program of China (2011CB013601) and the Major Research Plan of the National Natural Science Foundation of China under Grant no. 91315301-07, partially by the National Science Foundation under Grants nos. 51408560 and 51578514, and also in part by the Basic Research and Business Projects of Public Welfare Institutes under Central Level by Grant no. DQJB15B11.

\section{References}

[1] F. Khoshnoudian and B. Mehrparvar, "A new control algorithm to protect nonlinear base-isolated structures against earthquakes," The Structural Design of Tall and Special Buildings, vol. 22, no. 18, pp. 1376-1389, 2013.

[2] F. Mollaioli, A. Lucchini, Y. Cheng, and G. Monti, "Intensity measures for the seismic response prediction of base-isolated buildings," Bulletin of Earthquake Engineering, vol. 11, no. 5, pp. 1841-1866, 2013.

[3] A. Leopa, S. Nastac, and C. Debeleac, "Researches on damage identification in passive vibro-isolation devices," Shock and Vibration, vol. 19, no. 5, pp. 803-809, 2012.

[4] V. Briman and Y. Ribakov, "Using seismic isolation columns for retrofitting buildings with soft stories," The Structural Design of Tall and Special Buildings, vol. 18, no. 5, pp. 507-523, 2009.

[5] Y. Ribakov, "Base-isolated structures with selective controlled semi-active friction dampers," The Structural Design of Tall and Special Buildings, vol. 20, no. 7, pp. 757-766, 2011.

[6] Y. D. Shi, M. Kurata, and M. Nakashima, "Disorder and damage of base-isolated medical facilities when subjected to near-fault and long-period ground motions," Earthquake Engineering and Structural Dynamics, vol. 43, no. 11, pp. 1683-1701, 2014.

[7] G. Y. Yan and F. Q. Chen, "Seismic performance of midstory isolated structures under near-field pulse-like ground motion and limiting deformation of isolation layers," Shock and Vibration, vol. 2015, Article ID 730612, 17 pages, 2015.

[8] G. Ozdemir and U. Akyuz, "Dynamic analyses of isolated structures under bi-directional excitations of near-field ground motions," Shock and Vibration, vol. 19, no. 4, pp. 505-513, 2012.

[9] F. Oliveira, P. Morais, and A. Suleman, "A comparative study of semi-active control strategies for base isolated buildings," Earthquake Engineering and Engineering Vibration, vol. 14, no. 3, pp. 487-502, 2015.

[10] P. Castaldo, B. Palazzo, and P. Della Vecchia, "Seismic reliability of base-isolated structures with friction pendulum bearings," Engineering Structures, vol. 95, pp. 80-93, 2015.

[11] M. Q. Feng and A. Mita, "Vibration control of tall buildings using mega subconfiguration," Journal of Engineering Mechanics, vol. 121, no. 10, pp. 1082-1088, 1995. 
[12] W. Chai and M. Q. Feng, "Vibration control of super tall buildings subjected to wind loads," International Journal of NonLinear Mechanics, vol. 32, no. 4, pp. 657-668, 1997.

[13] Y. J. Tian, Vibration Damping Theory and Optimization Design Method for Multifunctional Vibration-Absorption of $R C$ Megaframe Structures, College of Civil Engineering, Southeast University, Nanjing, China, 2002.

[14] Z. J. Lan, Y. J. Tian, S. Y. Cao, and H. H. Wang, "The mechanism and efficiency of multifunctional vibration absorption for megaframe structures," China Civil Engineering Journal, vol. 35, no. 6, pp. 1-5, 2002.

[15] X.-Z. Pei and L. Wang, "Earthquake response analysis of megasuspended braced frame attached with damper," Journal of Vibration and Shock, vol. 30, no. 11, pp. 190-197, 2011.

[16] X. J. Qin, X. A. Zhang, L. Zou, Q. Q. Wang, and P. Jiao, "Research on active control of mega-sub controlled structure with dampers subjected to seismic loads," in International Multi-Conference of Engineers and Computer Scientists (IMECS '10), pp. 1055-1060, March 2010.

[17] X. J. Qin and X. A. Zhang, "Vibration controlling characteristics of a new improved mega-sub controlled structure subjected to random wind loads," in Proceedings of the International MultiConference of Engineers and Computer Scientists (IMECS '09), pp. 1342-1347, Hong Kong, March 2009.

[18] Z. Xun'an, W. Dong, and J. Jiesheng, "The controlling mechanism and the controlling effectiveness of passive mega-subcontrolled frame subjected to random wind loads," Journal of Sound and Vibration, vol. 283, no. 3-5, pp. 543-560, 2005.

[19] X. A. Zhang, X. J. Qin, S. Cherry, Y. D. Lian, J. L. Zhang, and J. S. Jiang, "A new proposed passive mega-sub controlled structure and response control," Journal of Earthquake Engineering, vol. 13, no. 2, pp. 252-274, 2009.

[20] Y. D. Lian, X. A. Zhang, and C. Sheldon, "Damping characteristics of friction damped braced frame and its effectiveness in the mega-sub controlled structure system," Earthquake Engineering and Engineering Vibration, vol. 6, no. 2, pp. 171-181, 2007.

[21] Y. D. Lian, X. J. Wang, and T. Li, "Analysis of seismic response for the mega-sub controlled frame with friction damper," in Chapter 6: Landscape Planning and Design, vol. 450-451 of Advanced Materials Research, pp. 1269-1273, 2012.

[22] T. Limazie, X. A. Zhang, and X. J. Wang, "Vibration control parameters investigation of the mega-sub controlled structure system (MSCSS)," Earthquake and Structures, vol. 5, no. 2, pp. 225-237, 2013.

[23] X. J. Qin, X. A. Zhang, and S. Cherry, "Study on semiactive control of mega-sub controlled structure by MR damper subject to random wind loads," Earthquake Engineering and Engineering Vibration, vol. 7, no. 3, pp. 285-294, 2008.

[24] F. L. Zhou, Y. Zhang, and P. Tan, “Theoretical study on story isolation system," China Civil Engineering Journal, vol. 42, no. 8 , pp. 1-8, 2009.

[25] J. P. Ou and G. Y. Wang, Structural Random Vibration, High Education Press, Beijing, China, 1998. 


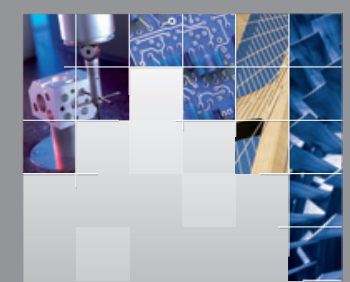

\section{Enfincering}
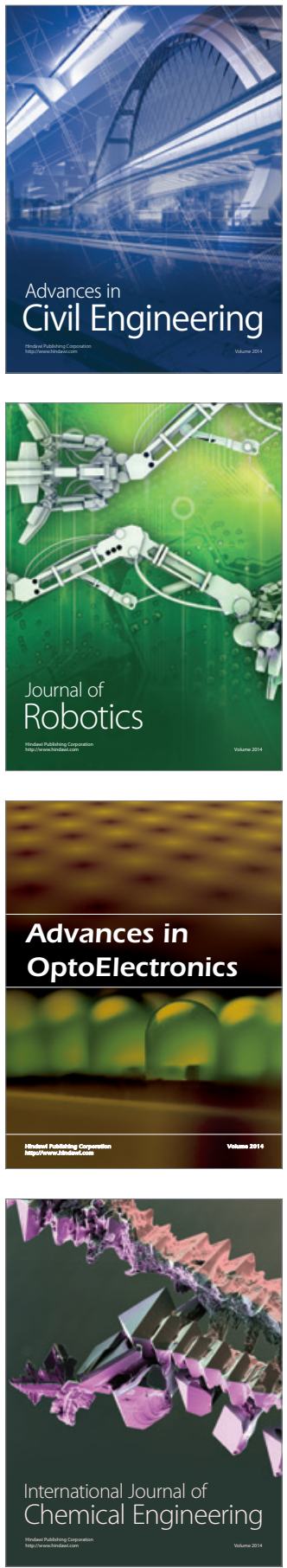

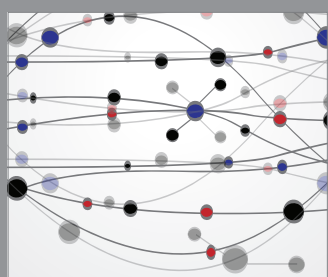

The Scientific World Journal

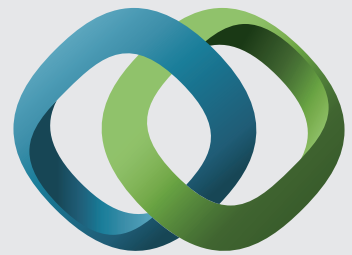

\section{Hindawi}

Submit your manuscripts at

http://www.hindawi.com
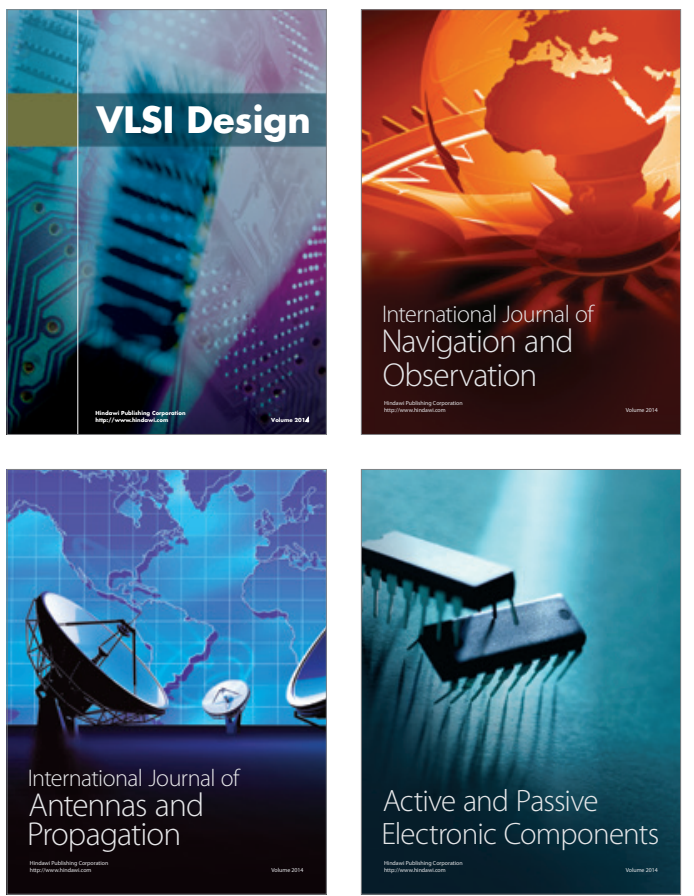
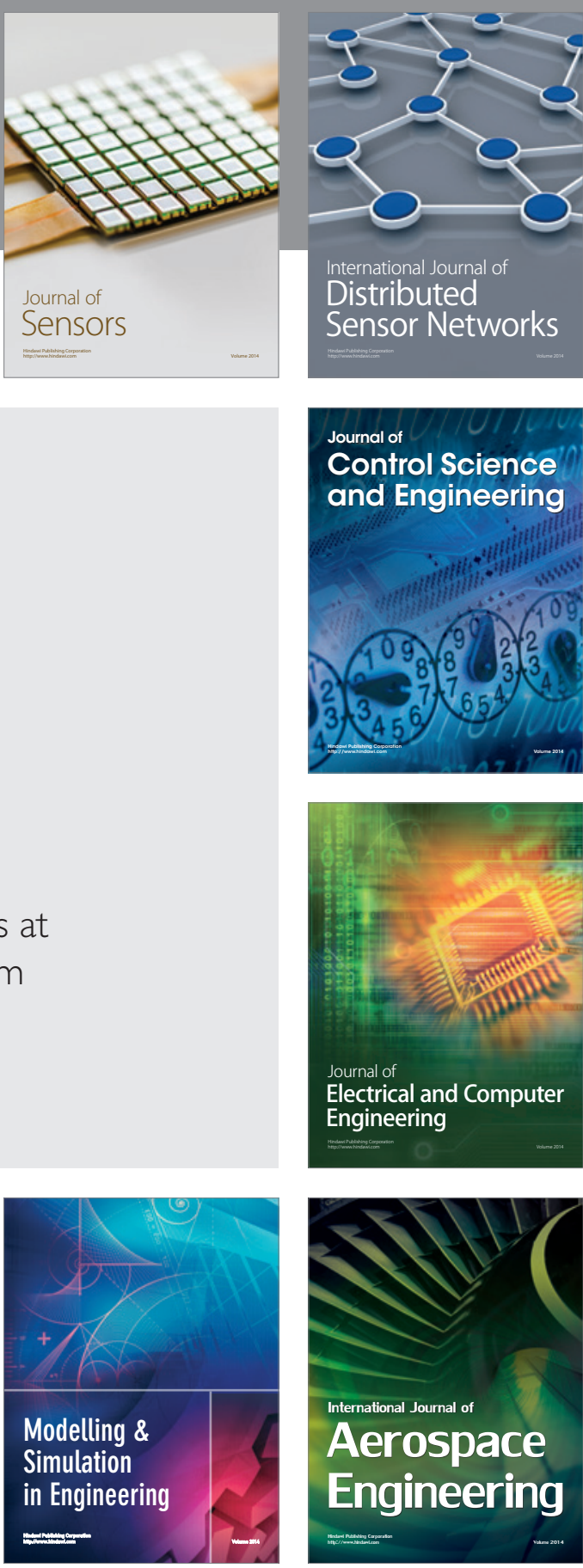

International Journal of

Distributed

Sensor Networks

Journal of

Control Science

and Engineering
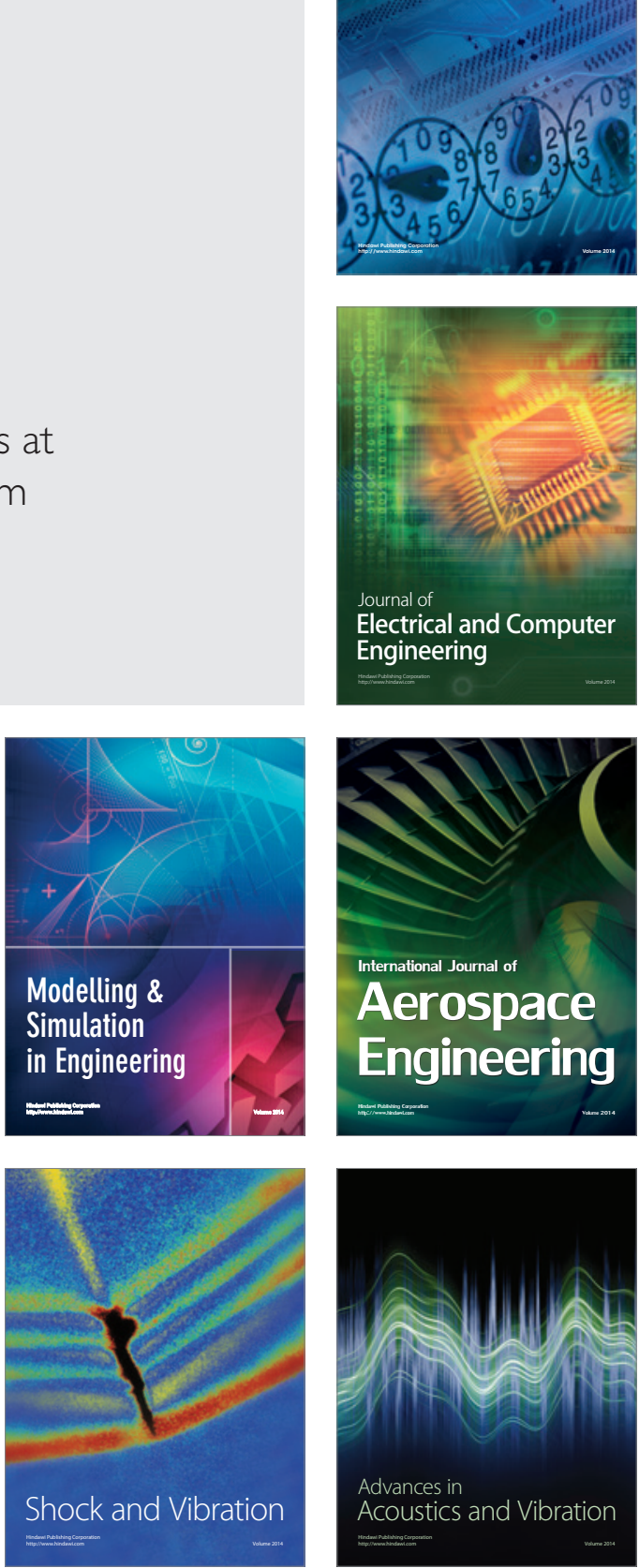